\title{
Induction of the Maize GapC4 Promoter in Transgenic Potato under Anaerobiosis and in Erwinia carotovora-Inoculated Tuber Tissue
}

\author{
Lorenz Bülow, ${ }^{1,2}$ Uwe Köhler, ${ }^{2}$ Rüdiger Cerff, ${ }^{2}$ Reinhard Hehl, ${ }^{2}$ and Klaus Düring ${ }^{1}$ \\ ${ }^{1}$ Federal Centre for Breeding Research on Cultivated Plants, Institute for Breeding Methods in Vegetables, \\ Neuer Weg 22 / 23, D-06484 Quedlinburg, Germany; ${ }^{\top}$ Technical University of Braunschweig, Institute \\ of Genetics - Biocenter, Spielmannstr. 7, D-38106 Braunschweig, Germany \\ Accepted 12 November 1998.
}

\begin{abstract}
The induction pattern of the GapC4 promoter from maize in transgenic potato has been analyzed by fusion to the $\beta$ glucuronidase (gus) gene. Under anaerobic conditions this promoter confers high level expression not only in leaves, stems, and roots but also in tubers. After inoculation of potato tuber disks with Erwinia carotovora subsp. atroseptica, $\beta$-glucuronidase (GUS) activity could be detected in macerated tissue as well as in surrounding intact tissue. In mock controls no induction was detected, ruling out any induction due to an overall limitation in oxygen in the experimental system. In addition, it could be proven that no diffusion of GUS protein from macerated into intact tissue occurred. The promoter was shown to be aerobically induced even in the absence of live bacteria by incubation with purified Erwinia spp. pectolytic enzymes alone. Therefore, promoter induction seems to be mediated by a mobile factor instead of by limitation in oxygen. These results demonstrate that the maize GapC4 promoter is suitable for directing foreign genes encoding antibacterial proteins in transgenic potato.
\end{abstract}

Additional keyword: resistance.

Expression of foreign proteins in transgenic plants for the development of new, efficient resistance strategies toward phytopathogenic bacteria such as Erwinia carotovora preferably should be directed by a promoter that is active under anaerobiosis, conditions under which the plant is most vulnerable to pathogen ingression. E. carotovora is facultatively anaerobic, resulting in a strong invasiveness under low oxygen conditions. In addition, only under aerobic conditions is potato partially resistant to this bacterium. Therefore, the highest probability of E. carotovora infection in potato under field conditions as well as during storage is under low oxygen (anaerobic) conditions. No genetic traits conferring resistance

Corresponding author: Klaus Düring; E-mail: klaus.during @t-online.de

Present address of Klaus Düring and Lorenz Bülow: MPB Cologne GmbH, Eupener Str. 161, D-50933 Köln, Germany; Telephone: +49-221 499 4725; Fax: +49-221 4994893.

Present address of Uwe Köhler: MRC Laboratory of Molecular Biology, Division of Cell Biology, Hills Road, Cambridge CB2 2QH, U.K. under these conditions are known in classically bred potato material.

Most known promoters are only active under aerobic conditions. For example, in maize only about 20 promoters are active in the absence of oxygen while all other genes are switched off (Sachs et al. 1980). The frequently used cauliflower mosaic virus (CaMV) 35 S promoter (Odell et al. 1985) is highly active in many dicotyledonous plants, e.g., tobacco and potato, under aerobic conditions almost constitutively. As shown here, this promoter is switched off under anaerobic conditions in potato. In genetic engineering strategies designed to counteract the invading phytopathogenic bacteria a high level of biologically active foreign protein should be synthesized. With the CaMV $35 \mathrm{~S}$ promoter or most of the other promoters available, no active synthesis of the foreign protein can be expected under the conditions most favorable to the pathogen.

Therefore, it is most useful to employ a promoter that is active under anaerobic conditions and to test this promoter under conditions of pathogen infection. For that purpose we have analyzed the induction pattern of the promoter of the maize cytosolic glyceraldehyde-3-phosphate dehydrogenase 4 (GapC4) gene in fusion with the $\beta$-glucuronidase $(g u s)$ reporter gene that previously had been described to be highly active in transgenic tobacco under anaerobic conditions (Köhler et al. 1996). The induction pattern in intact transgenic potato plants has been analyzed with the same test systems. In addition, potato tubers have been investigated under anaerobiosis. As a second analytical approach, a laboratory test system simulating an advanced stage of E. carotovora infection on potato tuber disks has been developed to reveal a putative induction after infection by this pathogen. The results of these studies are presented here and their implications for antibacterial resistance breeding by genetic engineering are discussed.

\section{RESULTS}

Northern blot analysis of transgenic p35S-T4 lysozyme potato plants.

Northern (RNA) hybridizations with the two independent transgenic potato lines DL4 and DL12 bearing a chimeric p35S-T4 lysozyme gene (Düring et al. 1993; P. Porsch and K. Düring, unpublished) were performed to demonstrate down- 
regulation of the CaMV 35S promoter under anaerobic conditions. After $12 \mathrm{~h}$ under anaerobic conditions no mRNA signal could be detected any longer in leaves whereas aerobic controls showed a strong signal (data not shown). In comparison, in transgenic p35S-gus potato lines $\beta$-glucuronidase (GUS) protein still could be detected in high amounts after 2 days under anaerobiosis, which is due to the exceptionally high stability of the GUS protein in plant cells (Table 1). These experiments demonstrate that the CaMV $35 \mathrm{~S}$ promoter is rapidly switched off under anaerobic conditions.

\section{Analysis of transgenic pGapC4-gus potato plants under anaerobic conditions.}

Independent transgenic pGapC4-gus potato lines have been developed by Agrobacterium tumefaciens-mediated transformation of potato cv. Désirée with the binary vector pUK 4030 (Köhler et al. 1996). This vector harbors a 785-bp maize GapC4 promoter fragment linked to the gus reporter gene. Twenty-two lines were tested by histochemical GUS staining of plants grown in vitro. Strong anaerobic induction of the GapC4 promoter was detected in almost all of the investigated transgenic lines. Most of them showed no expression under aerobic conditions as demonstrated in Figure 1A. Expression could be detected in leaves, stems, and roots. Only one trans-

Table 1. Fluorimetrically determined $\beta$-glucuronidase (GUS) activity in leaves and tubers

\begin{tabular}{|c|c|c|c|c|c|}
\hline \multirow[b]{3}{*}{ Line $^{a}$} & \multicolumn{5}{|c|}{ GUS activity in pmol MU $\times \mathrm{h}^{-1} \times \mu \mathrm{g}$ total soluble protein ${ }^{-1}$} \\
\hline & \multicolumn{2}{|c|}{ Leaves } & \multicolumn{3}{|c|}{ Tubers } \\
\hline & Aerobic & Anaerobic & Aerobic & Anaerobic & Macerated \\
\hline $1-5$ & $1,069.00$ & $1,329.37$ & 783.04 & 966.84 & 174.34 \\
\hline $1-6$ & 259.55 & 110.02 & 114.11 & 155.12 & 87.55 \\
\hline $1-7$ & 721.15 & 918.00 & 246.70 & 209.65 & 62.08 \\
\hline $1-8$ & 721.89 & 1573.00 & ND & ND & ND \\
\hline $2-8$ & 0.77 & 111.03 & 0.67 & 18.25 & 6.92 \\
\hline $2-10$ & 0.24 & 79.14 & 0.99 & 45.77 & 5.57 \\
\hline $2-11$ & 0.36 & 48.62 & 0.28 & 7.32 & 3.80 \\
\hline $2-12$ & 0.67 & 60.61 & 0.45 & 33.35 & 7.89 \\
\hline $2-13$ & 0.61 & 131.69 & 0.32 & 10.25 & 31.65 \\
\hline $2-14$ & 0.16 & 75.51 & 0.50 & 32.77 & 32.40 \\
\hline $2-15$ & 0.15 & 45.55 & 0.93 & 39.75 & 11.77 \\
\hline $2-16$ & 0.10 & 23.97 & 0.65 & 14.61 & 14.20 \\
\hline $2-17$ & 0.24 & 65.49 & 1.14 & 59.43 & 35.13 \\
\hline $2-18$ & 0.16 & 56.74 & 0.54 & 13.20 & 10.46 \\
\hline $2-19$ & 0.13 & 143.52 & 1.03 & 14.97 & 21.46 \\
\hline $2-20$ & 0.24 & 42.55 & 2.10 & 41.07 & 10.37 \\
\hline $2-21$ & 0.11 & 42.77 & 1.12 & 61.02 & 8.01 \\
\hline $2-22$ & 0.47 & 35.93 & 0.32 & 9.59 & 8.87 \\
\hline $3-1$ & 4.16 & 0.68 & 0.66 & 0.30 & 1.38 \\
\hline $3-2$ & 0.68 & 0.07 & 0.00 & 0.25 & 0.36 \\
\hline $4-5$ & 5.34 & 0.58 & 0.00 & 0.35 & 0.50 \\
\hline NT potato & 0.19 & 0.34 & 0.00 & 0.52 & 1.45 \\
\hline \multicolumn{6}{|c|}{ pRT 99 (tobacco) } \\
\hline & 47.41 & 90.19 & NA & NA & NA \\
\hline \multicolumn{6}{|c|}{ 404-8 (tobacco) } \\
\hline & 0.90 & 255.29 & NA & NA & NA \\
\hline \multicolumn{6}{|c|}{$\begin{array}{l}\text { a Independent transgenic potato lines } 40 \mathrm{~h} \text { after start of aerobic and an- } \\
\text { aerobic incubation and in fully macerated tuber tissue after inoculation } \\
\text { with the Erwinia carotovora subsp. atroseptica strain 549. Lines 1-5 to } \\
\text { 1-8: p35S-gus transgenic potato lines; lines 2-8 to 2-22: pGapC4-gus } \\
\text { transgenic potato lines; lines 3-1 and 3-2: promoterless-gus transgenic } \\
\text { potato control lines; line 4-5: transgenic potato control line trans- } \\
\text { formed with pOCA 28 only; line pRT99: p35S-gus transgenic tobacco } \\
\text { control line; line 404-8: pGapC4-gus transgenic tobacco control line. } \\
\mathrm{NT}=\text { nontransformed; ND = not determined; NA = not applicable. }\end{array}$} \\
\hline
\end{tabular}

genic plant line (line 2-2) did not show any expression of the gus gene at all. For comparison, p35S-gus (pSR 5-2) and promoterless-gus construct (pGUS) bearing plants have been tested. p35S-gus plantlets showed a strong signal under aerobic and anaerobic conditions whereas in promoterless-gus plants no expression could be detected at all (data not shown). These results demonstrate an efficient, non-tissue-specific expression of the GapC4 promoter in transgenic potato plants under anaerobic conditions.

\section{Analysis of pGapC4-gus potato tubers under anaerobic conditions.}

Expression of pGapC4-gus in potato tubers was analyzed in greenhouse-grown minitubers. Tuber disks were prepared and incubated for $40 \mathrm{~h}$ under anaerobic conditions. After that period, thin slices were cut with a scalpel and incubated in GUS buffer for histochemical staining. In 21 pGapC4-gus lines anaerobic induction was detected histochemically while no expression was obtained under aerobic conditions (Fig. 1B).

\section{Analysis of pGapC4-gus potato tubers after infection with $E$. carotovora subsp. atroseptica.}

For testing a putative induction of the GapC4 promoter under conditions when potato tubers have been infected by $E$. carotovora, we used a tuber disk infection system (Düring et al. 1993) that was adapted appropriately. Potato tubers were cut to disks of constant diameter. After fresh wounding by piercing with a needle, a suspension of E. carotovora subsp. atroseptica strain 549 was applied to the center of the tuber disk. These disks were placed in a plastic box on a wet filter paper so that the bacteria grew under conditions favorable for multiplication and tissue maceration. After $40 \mathrm{~h}$ the tuber disks were completely macerated.

To avoid background GUS activity from possible contaminating bacteria, potato tubers were sterilized prior to infection. E. carotovora itself does not possess any GUS activity, as confirmed by growth on agar plates supplemented with 5bromo-4-chloro-3-indolyl- $\beta$-D-glucuronic acid (X-gluc; data not shown). When nontransgenic tuber disks were macerated by $E$. carotovora and incubated in GUS staining buffer also no background signal could be detected.

The macerated tissue of tubers from seven independent pGapC4-gus lines was stained with the histochemical GUS test (Fig. 1C). Noninfected control disks showed no signal. Tubers of the control p35S-gus and promoterless-gus lines were tested in addition. p35S-gus tubers showed a signal with and without inoculation. The promoterless-gus tubers showed no expression at all.

To demonstrate that the observed induction was due to the inoculation with E. carotovora and not to an overall limitation in oxygen in the plastic boxes, pGapC4-gus tubers were placed in open boxes under a sterile air flow. Tuber tissue macerated by E. carotovora stained blue, indicating that induction is specifically conditioned by the bacterial infection. No blue staining was detected when only bacterial growth medium was applied to the tuber disks. As expected, the p35S-gus bearing control tubers showed strong blue staining for GUS activity in infected as well as in noninfected tubers after incubation under air flow.

A tuber disk assay with partial maceration of the tuber tissue was established in order to investigate if an infection with 
E. carotovora is able to induce the GapC4 promoter not only in the macerated parts of the tuber but also in intact surrounding tissue. Twenty-four hours after inoculation with $E$. carotovora, macerated tissue was separated from nonmacerated tissue. Thin sections were cut from the top of the re- maining intact part of the tuber disk and then incubated in a modified GUS buffer supplemented with streptomycin and Triton X-100 for inhibition of further tissue maceration during the staining reaction. The macerated area as well as the surrounding intact tissue of tuber disks of the pGapC4-gus lines

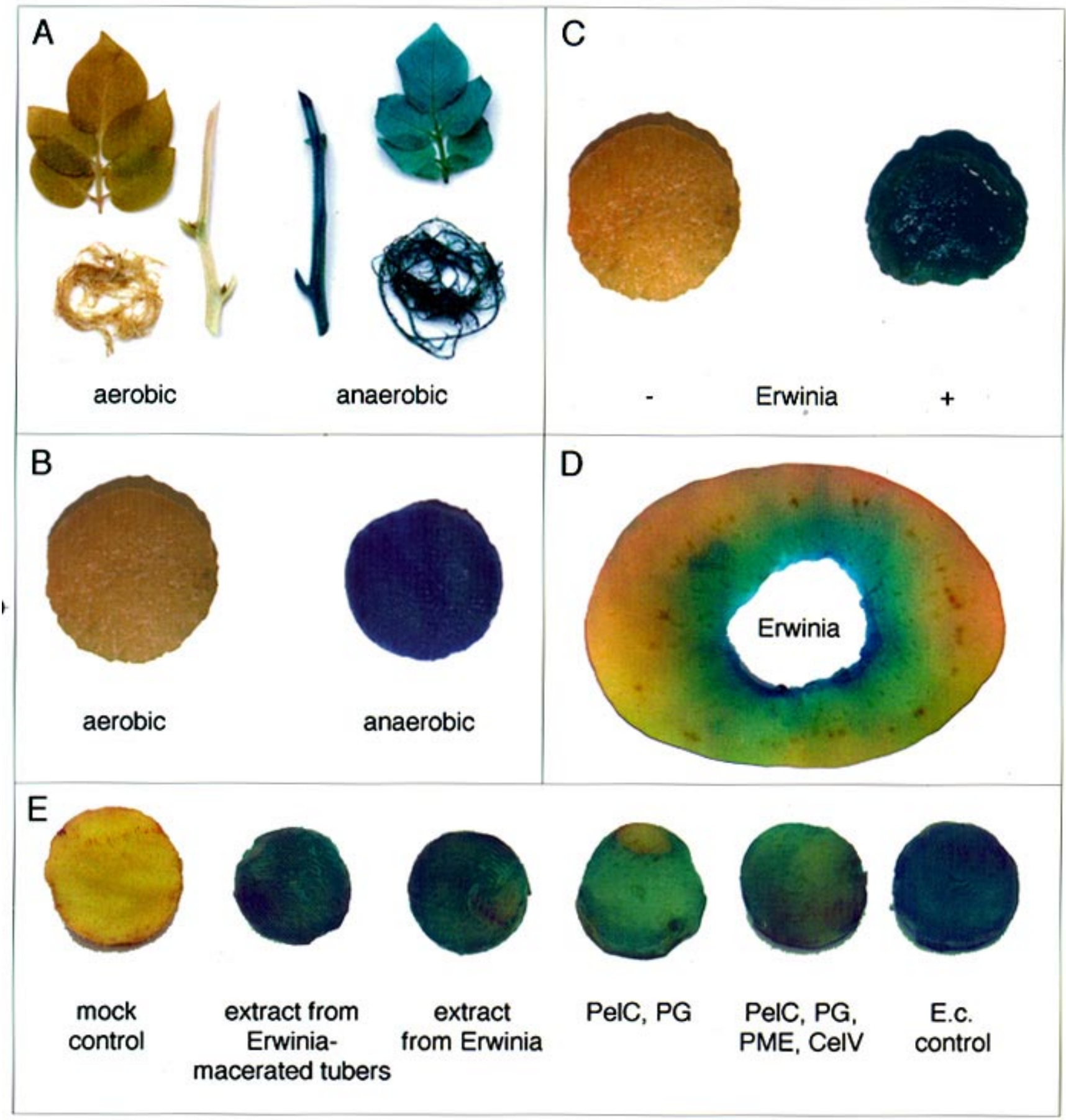

Fig. 1. Histochemically stained (A) leaves, stems, and roots, and (B) tuber disks, of a pGapC4-gus potato line after $40 \mathrm{~h}$ of aerobic and anaerobic incubation. Tissue was cleared from chlorophyll by ethanol extraction after gus staining. C, Histochemically stained tuber disks of a pGapC4-gus potato line $40 \mathrm{~h}$ after inoculation with Erwinia carotovora (right); left: mock control, freshly cut for staining. D, Histochemically stained partially macerated tuber disk of a pGapC4-gus potato line $24 \mathrm{~h}$ after inoculation with E. carotovora. Induction of the GapC4 promoter in intact tuber tissue surrounding macerated tuber tissue. E, Histochemically stained tuber disks of a pGapC4-gus potato line $40 \mathrm{~h}$ after inoculation with sterile extracts of E. carotovoramacerated tubers, of $E$. carotovora grown in medium, and different pectolytic enzymes and negative and positive controls (PelC: pectate lyase C from $E$. carotovora; PG: polygalacturonase from E. carotovora; PME: pectin methyl exterase from E. chrysanthemi; CelV: cellulase from E. carotovora). 
2-13 and 2-17 stained blue, indicating an induction of the GapC4 promoter also in the intact surrounding area (Fig. 1D). As induction was also observed at the outer surface of the tuber disks, oxygen limitation as a responsible causative factor for induction is not probable. Instead, induction of the GapC4 promoter by $E$. carotovora might be mediated by a mobile factor.

\section{Quantification of the induction factors in pGapC4-gus potato.}

The strength of the GapC4 promoter in potato was compared with that of the CaMV $35 \mathrm{~S}$ promoter in quantitative GUS assays. Fourteen independent transgenic pGapC4-gus potato lines and four $\mathrm{p} 35 \mathrm{~S}$ - gus potato lines were analyzed in a fluorimetric GUS test together with promoterless-gus and binary-vector-only controls. Leaves and tubers were incubated aerobically and anaerobically for $40 \mathrm{~h}$. GUS activity was determined by measurement of methylumbelliferone (MU) in pmol $\times$ hour $^{-1} \times \mu \mathrm{g}$ total soluble protein ${ }^{-1}$ (Table 1). In pGapC4-gus leaves after anaerobic induction measured values ranged from 23 to $143 \mathrm{pmol} \times$ hour $^{-1} \times \mu \mathrm{g}$ total soluble protein $^{-1}$ with an average of $68.8 \mathrm{pmol} \times$ hour $^{-1} \times \mu$ g total soluble protein $^{-1}$. Under aerobic conditions no significant activity could be detected, compared with the promoterless and nontransgenic controls. In two lines expression of the GapC4 promoter in leaves under anaerobic conditions was around $20 \%$ of the average GUS expression obtained with the strong CaMV $35 \mathrm{~S}$ promoter under aerobic conditions. The average of all 14 pGapC4-gus lines was about $10 \%$ of that for the p35S-gus lines.

In pGapC4-gus tubers, after anaerobic induction, the measured values ranged from 7 to $61 \mathrm{pmol} \times$ hour $^{-1} \times \mu$ g total solu-

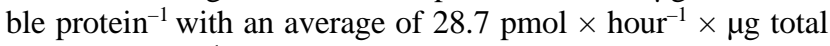
soluble protein ${ }^{-1}$. Again, two lines showed around $15 \%$ and on average all lines $7.5 \%$ of the activity of the p35S-gus lines under aerobic conditions.
Additionally, pGapC4-gus tubers fully macerated by $E$. carotovora within $40 \mathrm{~h}$ were analyzed (Table 1 ; Fig. 2). With an average of $14.9 \mathrm{pmol} \times$ hour $^{-1} \times \mu \mathrm{g}$ total soluble protein ${ }^{-1}$ about $50 \%$ of GUS expression compared with anaerobiosis was observed.

The induction factors for leaves and tubers under anaerobiosis and for E. carotovora-infected tubers obtained with the 14 pGapC4-gus lines are displayed in Table 2. On average, a 307-fold induction above background was detected for leaves after anaerobic incubation, with the highest factor being 1,100 -fold. For tubers on average a 38 -fold anaerobic induc-

Table 2. GapC4 promoter induction factors

\begin{tabular}{|c|c|c|c|}
\hline \multirow[b]{3}{*}{ Line } & \multicolumn{3}{|c|}{ Induction factors $^{\mathrm{a}}$} \\
\hline & \multirow{2}{*}{$\frac{\text { Leaves }}{\text { Anaerobic }}$} & \multicolumn{2}{|c|}{ Tubers } \\
\hline & & Anaerobic & Inoculated \\
\hline $2-8$ & 144.2 & 27.2 & 10.3 \\
\hline $2-10$ & 329.8 & 46.2 & 5.6 \\
\hline $2-11$ & 135.1 & 26.1 & 13.6 \\
\hline $2-12$ & 90.5 & 74.1 & 17.5 \\
\hline $2-13$ & 215.9 & 32.0 & 98.9 \\
\hline $2-14$ & 471.9 & 65.5 & 64.8 \\
\hline $2-15$ & 303.7 & 42.7 & 12.7 \\
\hline $2-16$ & 239.7 & 22.5 & 21.8 \\
\hline $2-17$ & 272.9 & 52.1 & 30.8 \\
\hline $2-18$ & 354.6 & 24.4 & 19.4 \\
\hline $2-19$ & $1,104.0$ & 14.5 & 20.8 \\
\hline $2-20$ & 177.3 & 19.6 & 4.9 \\
\hline $2-21$ & 388.8 & 54.5 & 7.2 \\
\hline $2-22$ & 76.4 & 30.0 & 27.7 \\
\hline Average & 307.5 & 38.0 & 25.4 \\
\hline
\end{tabular}

a Factors above background for anaerobic induction in potato leaves and tubers and for induction by the Erwinia carotovora subsp. atroseptica strain 549 in fully macerated potato tuber tissue. Induction factors are calculated from absolute values presented in Table 1.

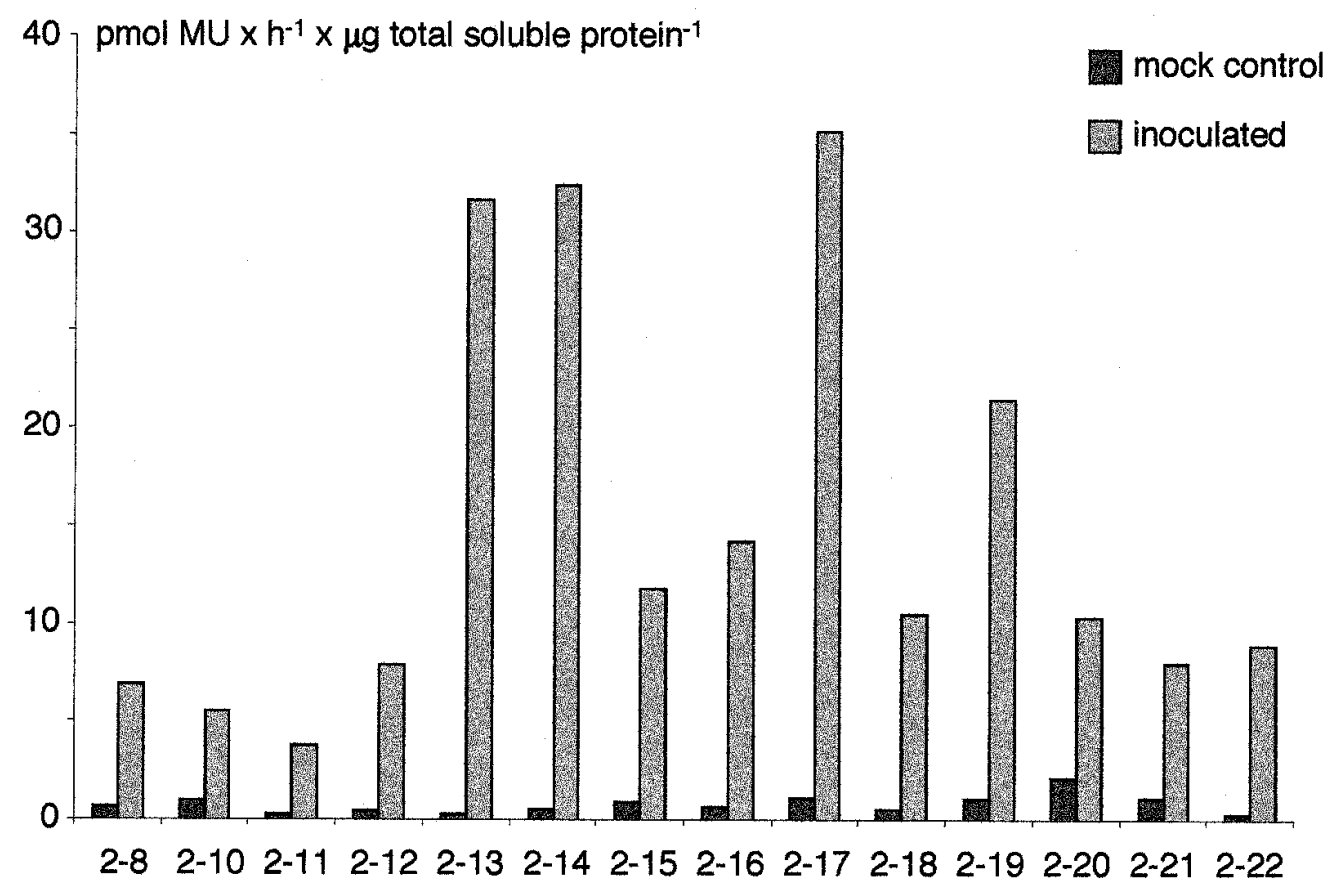

Fig. 2. Fluorimetric quantification of $\beta$-glucuronidase (GUS) activity in fully macerated tuber disks of 14 independent pGapC4-gus potato lines $40 \mathrm{~h}$ after inoculation with the Erwinia carotovora subsp. atroseptica strain 549 (right) and mock controls (left). 
tion was observed compared with the corresponding aerobic controls, the highest value being 74-fold. E. carotovora infected tubers showed on average a 25 -fold induction of the GapC4 promoter compared with the noninoculated controls, the highest factor being 99-fold.

For the pGapC4-gus lines 2-13 and 2-17 partially macerated tuber disks were analyzed $24 \mathrm{~h}$ after inoculation with $E$. carotovora (Fig. 3). The macerated inner circle of the tuber disk slice was scraped out for analysis. From the remaining intact tuber tissue protein was extracted in areas 0 to 2,2 to 4 , and approximately $20 \mathrm{~mm}$ distant from the border between macerated and intact tissue. An anaerobic, noninoculated control was analyzed in addition. The measured values demonstrate a decrease of promoter induction from the macerated to the intact tuber tissue. For GapC4-gus line 2-13, in direct neighborhood to the infected area $80 \%$ of activity was observed, at 2 to $4 \mathrm{~mm}$ distance about $50 \%$ expression was detected, and $20 \mathrm{~mm}$ away from the macerated part of the tuber GUS expression of about $30 \%$ of that in fully macerated tissue was still measured. In comparison, the noninfected control showed no significant expression (Fig. 3).

\section{Nature of the induction factor in the potato- $E$. carotovora interaction.}

To rule out that diffusion of the GUS protein could have revealed blue staining in intact tissue surrounding the macerated area the following test was performed. A p35S-gus tuber disk was placed on wet filter paper. Around this disk a ring of a nontransgenic potato tuber was placed. The inner circle was macerated by E. carotovora for release of produced GUS protein from the cells. Transgenic tissue and nontransgenic tissue were separately stained by incubation in GUS buffer. The inner circle showed a strong expression signal as expected whereas the outer ring did not stain blue at all, indicating that no diffusion of GUS protein from macerated into intact tissue had occurred.
In a second experiment, vice versa, the nontransgenic tissue was used as the inner disk and pGapC4-gus line 2-13 tuber tissue as the outer ring. After inoculation with E. carotovora and complete maceration of the inner disk both tissues were separately incubated in GUS staining buffer. The nontransgenic inner circle showed no positive signal whereas the intact transgenic outer ring stained blue in the region close to the contact face with the inner circle.

To further substantiate that GapC4 promoter induction is caused by a mobile factor the following experiments were conducted. E. carotovora was grown for $40 \mathrm{~h}$ on nontransgenic potato tuber slices. The completely macerated disks were homogenized and, after centrifugation, the supernatant was filter sterilized and applied to pGapC4-gus potato tuber disks. Forty hours later the transgenic tuber disks were macerated and incubation with GUS staining buffer revealed induction of the GapC4 promoter (Fig. 1E). Maceration of tuber slices indicated pectolytic enzyme activity of the extract from E. carotovora-macerated tubers, which was confirmed photometrically by measurement of polygalacturonic acid (PGA) degradation in vitro (data not shown).

Furthermore, a sterile extract from E. carotovora grown on medium with PGA as sole carbon source was used for incubation of pGapC4-gus potato tubers. After $40 \mathrm{~h}$, tuber disks were macerated and could be stained blue, indicating promoter induction (Fig. 1E). Also in this experiment pectolytic enzyme activity was detected photometrically (data not shown).

Supposing that enzymatic maceration of tuber tissue could release a diffusible factor responsible for promoter induction, purified Erwinia spp. pectolytic enzymes were applied to pGapC4-gus potato tuber disks. Two different compositions were used, one containing $0.5 \mu \mathrm{g}$ of polygalacturonase (PG), pectate lyase $\mathrm{C}$ (PelC), pectin methylesterase (PME), and cellulase V (CelV), and the other PG and PelC, only. Figure $1 \mathrm{E}$ shows that both enzyme compositions were able to macer-

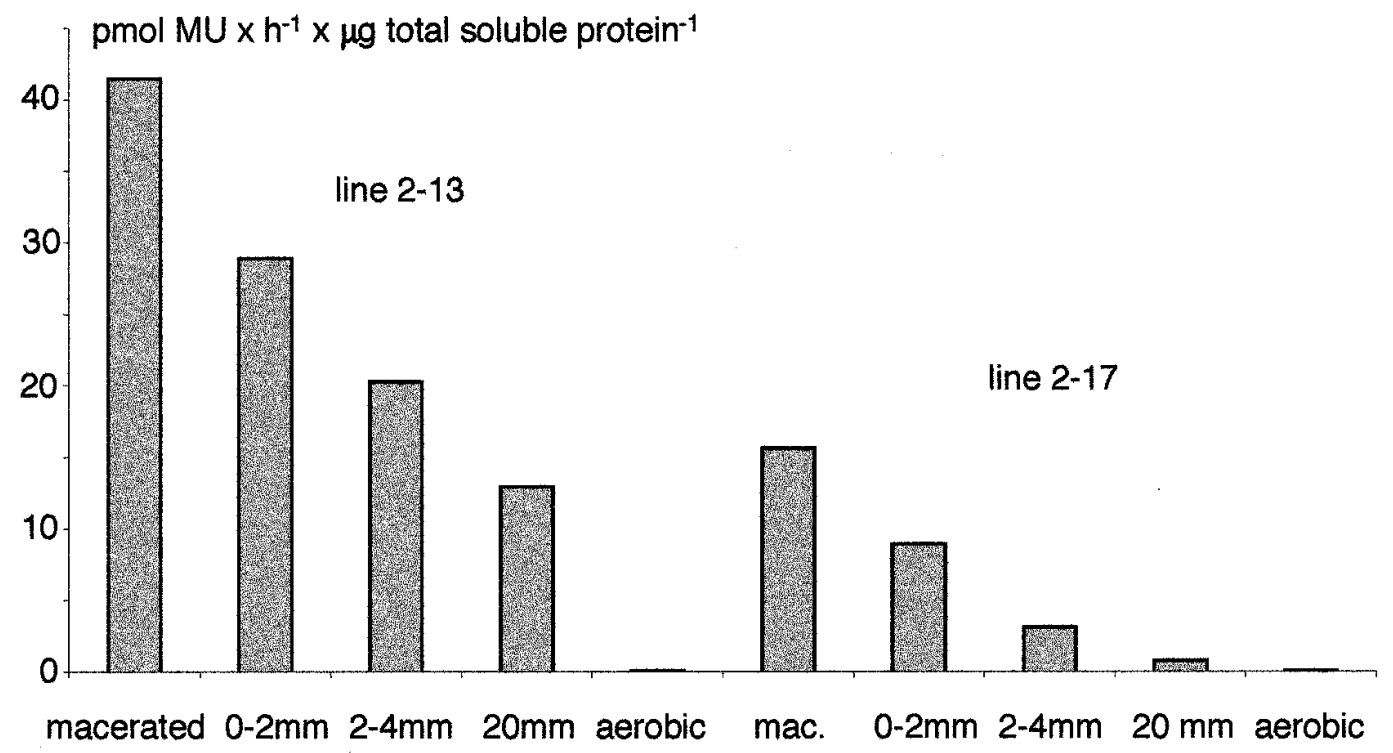

Fig. 3. Fluorimetric quantification of $\beta$-glucuronidase (GUS) activity in tuber disks of two pGapC4-gus potato lines in fully macerated tissue, in different distances from the border between macerated and nonmacerated tissue after inoculation with the Erwinia carotovora subsp. atroseptica strain 549 and aerobic, noninoculated, mock control. 
ate tuber tissue within $40 \mathrm{~h}$ of incubation, and GUS staining proved induction of the GapC4 promoter.

These experiments demonstrate that promoter induction occurs in the absence of live bacteria. Isolated pectolytic enzymes are able to induce the promoter. Taken together with the results ruling out passive diffusion of GUS as a cause for false positive data, this suggests the release of a mobile factor in the interaction between E. carotovora and potato by degradation of potato pectin. Therefore, promoter induction in $E$. carotovora-infected tissue seems to be mediated by this factor instead of by limitation in oxygen.

\section{DISCUSSION}

Induction of the maize GapC4 promoter under anaerobic conditions has already been observed in maize and transgenic tobacco (Köhler et al. 1995, 1996; Manjunath and Sachs 1997) and is reported here for transgenic potato. Therefore, its applicability for anaerobic expression of foreign genes in other plant species seems to be probable. We could show that no expression was observed in almost all transgenic potato lines under aerobic conditions whereas a strong induction of GUS activity by a factor of up to 1,100-fold was found under anaerobic conditions. Expression of the maize GapC4 promoter is not restricted to specific tissues but occurs in all macroscopically analyzed parts of the potato plant, including tubers, in a nonspecific manner. Storage organs had not yet been analyzed before for promoter activity in the respective plant species. In contrast to transgenic tobacco leaves (Köhler et al. 1995) the promoter is not induced by wounding in transgenic potato tubers, as demonstrated by cutting tuber disks.

The most stringent assay for investigation of the applicability of the maize GapC4 promoter to genetic engineering for resistance to phytopathogenic bacteria in transgenic potato is the tuber disk infection procedure. As we could observe GUS activity in macerated as well as in surrounding intact tuber tissue and we could rule out diffusion of the GUS protein itself as a putative false positive factor, induction of the GapC4 promoter seems to be mediated by a mobile signal. Strong evidence supporting this assumption was gathered in applying purified pectolytic enzymes from Erwinia spp. They are able to induce the GapC4 promoter without any necessity for presence of live bacteria. As the occurrence of protein mobility was ruled out, a mobile factor responsible for promoter induction seems to be released during degradation of plant cell wall pectin due to the activity of bacterial pectolytic enzymes.

This should enable induction early enough before massive tissue degradation by a huge number of bacterial cells occurs. The controls we have used demonstrate that induction under the chosen conditions is not due to an overall experimental restriction in oxygen supply in the moist chambers. Either the conditions in tuber tissue areas where bacteria are actively growing are anaerobic, which is less likely at the outer surface, or another, yet unknown factor stimulated by the presence of pectolytic enzymes produced by E. carotovora is involved in the regulation of promoter activity.

The results obtained from this study confirm the anaerobic induction of the maize GapC4 promoter also in potato. Unexpectedly, we also discovered that E. carotovora infection in potato tubers under aerobic conditions leads to induction of this GapC4 promoter in infected as well as in surrounding, noninfected, healthy tuber tissue. Recent experiments revealed that lysozyme mRNA driven by the GapC4 promoter already is detectable after $8 \mathrm{~h}$ of anaerobic induction (L. Bülow, unpublished result). Therefore, we assume that induction occurs early enough for directing expression of antimicrobial proteins for resistance to E. carotovora. In conclusion, the promoter might be highly valuable for application in antibacterial genetic engineering strategies in potato. In addition, we can speculate on the basis of our investigation that similar induction might also occur in other host plants. Consequently, its applicability may be broadened at least to all host plants of $E$. carotovora.

Currently, we are investigating transgenic plants carrying a pGapC4-T4 lysozyme chimeric construct. T4 lysozyme has already proved to confer enhanced resistance to E. carotovora under the control of the CaMV 35S promoter (Düring et al. 1993). Future experiments will reveal if active synthesis of this antimicrobial protein under anaerobiosis enhances the resistance effect further and if induction under aerobic conditions by E. carotovora occurs early and strong enough to mediate this effect.

\section{MATERIALS AND METHODS}

\section{Plasmid constructs.}

Plasmids pUK 4030 and pGUS used for plant transformation were described by Köhler et al. (1996). For the construction of the p35S-gus plasmid the binary vector pCMVGUS3 (R. Hehl, unpublished) was digested with $P v u I I$ and the fragment harboring the p35S-gus gene was cloned into the SmaI site of pOCA 28 (Honma et al. 1993; Olszewski et al. 1988), resulting in plasmid pSR 5-2. Recombinant DNA techniques were performed according to standard protocols (Sambrook et al. 1989). Binary vectors were transferred to the Agrobacterium tumefaciens strain EHA 101 (Hood et al. 1993).

\section{Potato transformation.}

A. tumefaciens-mediated transformation of potato cv. Désirée was performed as described by Düring et al. (1993) with the following modifications: callus growth was induced by placing leaves on MS (Murashige and Skoog) medium with $1.6 \%$ glucose, $5 \mathrm{mg}$ of NAA (naphthalene acetic acid) per liter, $0.1 \mathrm{mg}$ of BAP (6-benzylaminopurine) per liter, $250 \mathrm{mg}$ of cefotaxime per liter, and $50 \mathrm{mg}$ of kanamycin per liter. After 1 week, leaves were transferred to shoot-inducing medium (MS with $1.6 \%$ glucose, $2 \mathrm{mg}$ of zeatinriboside per liter, $20 \mu \mathrm{g}$ of NAA per liter, $20 \mu \mathrm{g}$ of $\mathrm{GA}_{3}$ (gibberellic acid $\mathrm{A}_{3}$ ) per liter, 250 $\mathrm{mg}$ of cefotaxime per liter, and $50 \mathrm{mg}$ of kanamycin per liter).

\section{Anaerobic induction.}

For histochemical and quantitative GUS assays plants and tubers were placed on petri dishes with wet filter paper and incubated in an airtight glass container (Merck, Darmstadt, Germany) together with Anaerocult A (Merck) for $40 \mathrm{~h}$. The container was placed inside a plant growth chamber at $22^{\circ} \mathrm{C}$ with $16 \mathrm{~h} / 8 \mathrm{~h}$ light/dark cycles. Aerobic controls were incubated on petri dishes under the same conditions but without the anaerobic container.

\section{$\beta$-Glucuronidase assay.}

Histochemical and quantitative fluorimetric GUS assays were performed as described by Jefferson et al. (1987). After 
inoculation with E. carotovora, thin slices of nonmacerated potato tuber tissue were prepared and incubated in GUS staining buffer supplemented by $100 \mathrm{mg}$ of streptomycin per liter in order to stop bacterial growth and by $0.5 \%$ Triton $\mathrm{X}$ 100 for better penetration.

\section{Northern blot.}

Leaves were cut from p35S-T4 lysozyme potato plants (Düring et al. 1993) and incubated for $12 \mathrm{~h}$ under anaerobic conditions as described above. Total RNA was extracted from $100 \mathrm{mg}$ of tissue with the RNeasy plant mini kit (Qiagen, Hilden, Germany). Approximately $20 \mu \mathrm{g}$ of total RNA was separated on a formaldehyde agarose gel and blotted onto a positively charged nylon membrane (Boehringer Mannheim, Mannheim, Germany). Hybridization was carried out with a digoxigenin (DIG)-labeled (Boehringer Mannheim) T4 lysozyme antisense RNA probe. Detection was performed with the Boehringer Mannheim Chemiluminescense Kit according to the manufacturer's protocol.

\section{Potato tuber disk assay.}

Tubers were sterilized by submerging them in a $1 \%$ sodium hypochloride solution for $15 \mathrm{~min}$ for elimination of potential bacterial contamination that may result in background GUS activity. After the tubers were washed with sterile water, inoculation was performed according to Düring et al. (1993) with the E. carotovora subsp. atroseptica strain 549 (National Collection of Plant Pathogenic Bacteria, Harpenden, UK). GUS assays with inoculated tissue were performed as described above.

\section{Extracts from $E$. carotovora-macerated potato tubers and $E$. carotovora cells.}

Extracts from E. carotovora-macerated tubers were produced by infecting sterile tuber slices from nontransgenic potato cv. Désirée with E. carotovora subsp. atroseptica 547. Bacteria were grown for $40 \mathrm{~h}$ in a sterile cultivation chamber at $28^{\circ} \mathrm{C}$. After that time, potato tissue was completely macerated. An equal volume of Erwinia medium (2 $\mathrm{g}$ of $\left(\mathrm{NH}_{4}\right)_{2} \mathrm{SO}_{4}$ per liter, $4 \mathrm{~g}$ of $\mathrm{KH}_{2} \mathrm{PO}_{4}$ per liter, $6 \mathrm{~g}$ of $\mathrm{Na}_{2} \mathrm{HPO}_{4}$ per liter, 0.2 $\mathrm{g}$ of $\mathrm{MgSO}_{4}$ per liter, $1 \mathrm{mg}$ of $\mathrm{FeSO}_{4} \times 7 \mathrm{H}_{2} \mathrm{O}$ per liter, and $1 \mathrm{mg}$ of $\mathrm{CaCl}_{2}$ per liter, $\mathrm{pH}$ 6.7) was added to and mixed with the macerated tissue. The resulting suspension was homogenized with an Ultra-turrax T8 dispersing instrument and centrifuged three times, and the supernatant was sterilized by filtration. Twenty microliters of the supernatant was applied to each tuber disk.

To obtain bacterial extract, $200 \mathrm{ml}$ of Erwinia medium supplemented by $0.1 \%$ polygalacturonic acid was inoculated with E. carotovora and incubated at $28^{\circ} \mathrm{C}$ on a shaker. Bacteria were harvested by centrifugation. The pellet was resuspended in $2 \mathrm{ml}$ of Erwinia medium. One hundred microliters of hen egg white lysozyme $(10 \mathrm{mg} / \mathrm{ml})$ was added to destroy cell walls. Cell debris was separated by centrifugation three times. The supernatant was sterilized by filtration. Ten microliters was used for each tuber disk.

As a positive control, $10 \mu \mathrm{l}$ of an E. carotovora subsp. atroseptica suspension was applied to the tuber disk. The negative control consisted of $10 \mu \mathrm{l}$ of Erwinia medium, only. GapC4-gus tuber slices were incubated for $40 \mathrm{~h}$ at $28^{\circ} \mathrm{C}$ in a growth chamber under sterile conditions. GUS staining was performed as described above.

\section{ACKNOWLEDGMENTS}

This work was supported by a grant to K. D. and R. H. from the Deutsche Forschungsgemeinschaft (Du 205/6-1). We thank Thomas Winkler for generous gifts of purified Erwinia spp. pectolytic enzyme samples.

\section{LITERATURE CITED}

Düring, K., Porsch, P., Fladung, M., and Lörz, H. 1993. Transgenic potato plants resistant to the phytopathogenic bacterium Erwinia carotovora. Plant J. 3:587-598.

Honma, M. A., Baker, B. J., and Waddell, C. S. 1993. High-frequency transposition of Ds-ALS in Arabidopsis. Proc. Natl. Acad. Sci. USA 90:6242-6246.

Hood, E. E., Gelvin, S. B., Melchers, L. S., and Hoekema, A. 1993. New Agrobacterium helper plasmids for gene transfer to plants. Transgen. Res. 2:208-218.

Jefferson, R. A., Kavanagh, T. A., and Bevan, M. 1987. GUS-fusions: $\beta$ Glucuronidase as a sensitive and versatile gene fusion marker in high plants. EMBO J. 6:3901-3907.

Köhler, U., Liaud, M.-F., Mendel, R. R., Cerff, R., and Hehl, R. 1995. The maize GapC4 promoter confers anaerobic reporter gene expression and shows homology to the maize anthocyanin regulatory locus C1. Plant Mol. Biol. 29:1293-1298.

Köhler, U., Mendel, R., Cerff, R., and Hehl, R. 1996. A promoter for strong and ubiquitous anaerobic gene expression in tobacco. Plant $\mathrm{J}$. 10:175-183.

Manjunath, S., and Sachs, M. M. 1997. Molecular characterization and promoter analysis of the maize cytosolic glyceraldehyde 3-phosphate dehydrogenase gene family and its expression during anoxia. Plant Mol. Biol. 33:97-112.

Odell, J. T., Nagy, F., and Chua, N. H. 1985. Identification of DNA sequences required for activity of the cauliflower mosaic virus $35 \mathrm{~S}$ promoter. Nature 313:810-812.

Olszewski, N. E., Martin, F. B., and Ausubel, F. M. 1988. Specialized binary vector for plant transformation: Expression of the Arabidopsis thaliana AHAS gene in Nicotiana tabacum. Nucleic Acids Res. 16: 10765-10782.

Sachs, M. M., Freeling, M., and Okimato, R. 1980. The anaerobic proteins of maize. Cell 20:761-767.

Sambrook, J., Fritsch, E. F., and Maniatis, T. A. 1989. Molecular Cloning: A Laboratory Manual. 2nd ed. Cold Spring Harbor Laboratory, Cold Spring Harbor, NY. 